\title{
Vitamins a and D Enhance the Expression of Ror- $\gamma-$ Targeting MiRNAs in a Mouse Model of Multiple Sclerosis
}

Marziyeh Mohammadi kordkhayli

Hotchkiss Brain Institute

Mohammd Ali Sahraian

Tehran University of Medical Sciences

Samira Ghorbani

Hotchkiss Brain Institute

Fatemeh Mansuri

Tehran University of Medical Sciences

Farideh Talebi

Shahed University

Farshid Noorbakhsh

Tehran University of Medical Sciences

Ali Akbar Saboor-Yaraghi ( $\nabla$ asaboor@tums.ac.ir)

Tehran University of Medical Sciences https://orcid.org/0000-0001-8612-4773

\section{Research Article}

Keywords: Multiple sclerosis, Experimental autoimmune encephalomyelitis, Vitamin A, Vitamin D, microRNA, T helper 17

Posted Date: December 10th, 2021

DOI: https://doi.org/10.21203/rs.3.rs-1091850/v1

License: (c) (1) This work is licensed under a Creative Commons Attribution 4.0 International License. Read Full License 


\section{Vitamins A and D enhance the expression of Ror- $\gamma$-targeting miRNAs in a mouse model of multiple sclerosis}

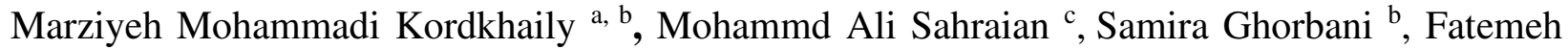
Mansuri $^{\text {a }}$, Farideh Talebi ${ }^{\text {d }}$, Farshid Noorbakhsh ${ }^{\text {e,f* }}$ and Ali Akbar Saboor-Yaraghi a *

${ }^{\text {a }}$ Department of Immunology, School of Public Health, Tehran University of Medical Sciences, Tehran, Iran

${ }^{\mathrm{b}}$ Hotchkiss Brain Institute and Department of Clinical Neurosciences, University of Calgary, Alberta, Canada

${ }^{c}$ Sina MS Research Center, Sina Hospital, Tehran University of Medical Sciences, Tehran, Iran

${ }^{\mathrm{d}}$ Immunoregulation Research Center, Shahed University, Tehran, Iran

${ }^{\text {e }}$ Shefa Neuroscience Research Center, Khatam Alanbia Hospital, Tehran, Iran

${ }^{\mathrm{f}}$ Department of Immunology, School of Medicine, Tehran University of Medical Sciences, Tehran, Iran

\section{Corresponding authors:}

Ali Akbar Saboor-Yaraghi, Department of Immunology, School of Public Health, Tehran University of Medical Sciences, Tehran, Iran

Email: asaboor@tums.ac.ir

Farshid Noorbakhsh, Department of Immunology, School of Medicine, Tehran University of Medical Sciences, Tehran, Iran

Email: f-noorbakhsh@sina.tums.ac.ir 


\begin{abstract}
Background: Multiple Sclerosis (MS) is an autoimmune disease of the central nervous system. Autoreactive T cells including cells with a Th17 phenotype are critical players in MS pathogenesis. In this study, we investigated the effects of VitA/D on miRNAs expression involved in Th17 development neuroinflammation using (EAE).
\end{abstract}

Methods: EAE was induced in C57BL/6 mice and received IP injections of vitamins A, D or their combination starting one day before the immunization and continued every other day for 30 days. Animals were scored for 30 days. Percentages of Th17 cells were measured in splenocytes following in vitro re-stimulation with MOG using intracellular staining and flow cytometry. Expression of miR-98-5p and Let-7a-5p, two miRNAs that are known to target Ror-t and Ror-t was measured in MOG-stimulated splenocytes as well as in spinal cord tissues using real-time RTPCR.

Results: Treated mice showed decreased frequency of Th17 cells in their spleens following in vitro re-stimulation with antigen, also lower expression of IL17 and Ror-t in their in CNS and splenocytes. Vitamin A and vitamin D-treated splenocytes showed significant upregulation of miR-98-5p in 24 hour and 48 hours time-points and Let-7a-5p expression was induced at 48-hour post-treatment in MOG-treated cells, which showed a strong negative correlation with splenocyte Ror-t levels.

Conclusion: Our data suggest that treatment with vitamins A and D can decreased differentiation of Th17 phenotype. This is likely due to upregulation of Ror-t-targeting miRNAs, miR-98-5p and Let-7a-5p following treatment. These findings point to a potential protective role for miRNAs in the context of autoimmune neuroinflammation.

Keywords: Multiple sclerosis, Experimental autoimmune encephalomyelitis, Vitamin A, Vitamin D, microRNA, T helper 17 


\section{Introduction}

Multiple sclerosis (MS) is an immune-mediated disorder which is characterized by inflammation and demyelination in the central nervous system (CNS) [1]. MS is chiefly a T cell-mediated disease and auto-reactive $\mathrm{T}$ cells which infiltrate the CNS are known as the key elements of the neuroinflammatory process $[2,3]$. Before the discovery of Th17 cells, interferon- $\gamma$-producing Th1 cells were believed to be the main pathogenic players in MS [1]. Recent evidence, however, has given more weight to IL-17-producing Th17 cells [4, 5]. Th17 cells and their cytokines are present in MS brain lesions and CSF, respectively. These cells have the ability to disrupt blood brain barrier (BBB), infiltrate the CNS and recruit more inflammatory cells to the site of injury [6, 7]. In addition to boosting the inflammatory response, Th17 cells have the ability to directly harm neurons and oligodendrocytes [7, 8]. Several treatments for MS are known to decrease the frequency of Th17 cells in the peripheral blood [9-14]. Similar findings have been reported in experimental autoimmune encephalomyelitis (EAE), a widely used animal model for MS. On note, elimination of Th17 cells can suppress the development of EAE and/or decrease the severity of clinical symptoms [7].

The aetiology of MS and the factors that initiate the damaging neuroinflammation in MS are unknown. Among the proposed factors are genetic predisposition, epigenetic alterations in gene expression and environmental factors [15-18]. Nutritional factors have long been considered as potential players in MS disease process [19-21]. Among micronutrients, different lines of evidence point to the role of vitamin D and vitamin A in development and progression of MS [22-26]. Evidence with regard to the role of vitamin D includes epidemiological, clinical and cell/molecular studies. At the cell and molecular levels, vitamin D supplementation has been shown to exert considerable effects on immune cell activation in MS patients and EAE mice [27], including downregulation Th17 cell differentiation and $\mathrm{CD} 8+\mathrm{T}$ cell cytokine production as well as enhancing regulatory T-cell (Treg) activity [28]. Likewise, epidemiological and immunological data have linked vitamin A and its analogs with MS disease. Of note, studies have indicated that vitamin A can reduce immune activation and CNS injury in MS/EAE [29-31].

MicroRNAs are a group of non-coding RNA with 19-22 nucleotides length that regulate the expression of various genes in a post-transcriptional manner [32]. MicroRNAs play important roles in a variety of physiological and pathological processes, including the regulation of innate and adaptive immune responses $[33,34]$. These functions are partly mediated through regulation of 
immune cell differentiation [35]. In particular, there is abundant evidence pointing to the role of miRNAs in regulation of T cell differentiation in health and disease [36-39]. Studies have shown that several miRNAs are involved in regulating Th17 cell differentiation and in Th17/Treg balance. Studies on miRNAs in different autoimmune diseases have supported the view that miRNA dysregulation is not only associated with but also exerts pathogenic roles in these disorders [4042]. Of note, investigations into the pathogenesis of MS using either human samples or EAE mice have shown that miRNA dysregulation occurs both in the CNS and in peripheral immune system in MS/EAE and influences the pathogenic process at different levels [43-48].

In the current study, we aimed to investigate the role of vitamin A, D and their combination on the severity of autoimmune neuroinflammation using EAE animal model. We first performed experiments to evaluate the effects of vitamin treatment on EAE disease severity. This was followed by analyzing the expression of IL17 and frequency of myelin reactive Th17 cells in splenocyte cultures. We next analyzed miRNAs which could target Th17 key transcription factor ror- $\gamma$ and their relation with ror- $\gamma$ expression.

\section{Materials and Methods}

\section{Animals}

six to eight week-old, inbred female C57BL/6 wild-type (WT) mice were purchased from Pasteur Institute of Iran. Animals were accommodated in standard controlled conditions with a 12-hour light/dark cycles, $20 \pm 2^{\circ} \mathrm{C}$ temperature with free access to nutrition and water. All experiments and animal care methods were approved by the Ethics Committee on Animal Experimentation of Tehran University of Medical Sciences.

\section{EAE Induction and Neurological assessment}

EAE was induced as previously described [27]. Briefly, 10 week-old C57BL/6 mice were immunized by subcutaneous (s.c) injections of $100 \mu \mathrm{g}$ myelin oligodendrocyte glycoprotein (MOG) 35-55 peptide emulsified in complete Freund's adjuvant. Mice also received two intraperitoneal (i.p) injections of pertussis toxin in PBS at $200 \mathrm{ng} / \mathrm{mouse} / \mathrm{dose}(0.1 \mathrm{ml})$ on the day of immunization and $48 \mathrm{~h}$ post immunization, as instructed by the manufacturer (EK-2110, Hooke 
$\mathrm{Kit}^{\mathrm{TM}}$ MOG 35-55/CFA Emulsion PTX). All groups' clinical scores were measured daily for up to 30 days after MOG immunization using a 0-to-15-point scoring scale [49].

\section{Experimental design}

Animals were divided into 5 groups, each with seven or eight animals, as follows: group I (healthy controls) were mice that did not receive MOG injection and were treated with vehicle; group II (EAE group) were EAE mice that were treated with the vehicle; group III (vitamin A-treated EAE group) were EAE mice that were given $100 \mathrm{ng}$ vitamin A (ATRA, all-trans-retinoic acid) per mouse; group IV (vitamin D-treated EAE group) were EAE mice that received $200 \mathrm{ng}$ calcitriol per mouse; and group V (vitamins A and D-treated EAE group) received a combination of vitamins A and D but with half a dose (50 ng and $100 \mathrm{ng}$ ). Vitamins A and D were obtained from Kern Pharma (Spain) and Sigma-Aldrich (St. Louis, MO, USA). All treatments were given intraperitoneally every day from 1 day before the immunization to 30 days post-immunization. After day 30, animals were scarified, and spleen and CNS tissues were removed under sterile conditions. Samples of spinal cord tissue were stored at $-80 \mathrm{C}$ freezers.

\section{Splenocytes culture and MOG Stimulation}

Splenocyte cultures were prepared from MOG-immunized C57BL/6 mice. Briefly, spleen tissues were homogenized and splenocytes were isolated using Ficoll density gradient centrifugation. $2 \times 10^{6}$ cells were cultured in each well with $(10,40 \mu \mathrm{g} / \mathrm{ml})$ concentrations of MOG35-55 (MOG in TC Media, 100×, Hooke labs) in RPMI 1640 medium (Gibco) supplemented with 5\% FBS (Gibco). The cells were harvested at 24 and 48 hours after incubation at $37^{\circ} \mathrm{C}$.

\section{Flow cytometry}

Splenocyte cultures were exposed to MOG35-55 $(40 \mu \mathrm{g} / \mathrm{ml})$ for 24 hours for antigen-specific stimulation and or PMA $(50 \mathrm{ng} / \mathrm{ml})$ and ionomycin $(1 \mu \mathrm{g} / \mathrm{ml})$ for 6 hours for polyclonal activation. Control group consisted of cells that were not stimulated with MOG35-55 or PMA + ionomycin. Cells were first surface stained with anti-CD4 and anti-CD3 antibodies. Next, cells were fixed with $1 \mathrm{ml} /$ tube Bio Legend's Fixation Buffer, kept at room temperature in the dark for 25 minutes and 
then permeabilized with $1 \mathrm{ml}$ Bio Legend's Permeabilization Buffer $(1 \times)$. Following fixation/Permeabilization cells were stained with fluorochrome-conjugated anti-IL-17A antibodies (BioLegend) according to manufacturer's instructions. Samples were analyzed on a BD FACS Calibur and results were analyzed by FlowJo software.

\section{RNA isolation and cDNA synthesis}

Total RNA was extracted from activated splenocyte cultures and lumbar spinal cord tissues using miRNeasy Mini Kit (Qiagen) and kept at $80^{\circ} \mathrm{C}$ according to the manufacturer's instructions. The RNA concentrations were determined by Nanodrop spectrophotometer system (Thermo Scientific) cDNA was prepared miScript II RT Kit (Qiagen) for miRNA studies, and TAKARA cDNA synthesis kit for mRNA analyses, following manufacturer's instructions.

\section{Real-time RT-PCR}

RT-PCR was used to evaluate the expression of miRNA and mRNAs in splenocyte cultures and spinal cord tissue. RT-PCRs were done using the Step One Plus Real Time PCR system. Table 1 shows the sequences of the primers that were used. The $\beta$-actin gene was used as a housekeeping gene for the normalization of the amplified signals of the target genes. snord68 and snord72 were used to normalize miRNA expression and the method of relative quantification $\left(2^{\Delta \Delta C t}\right)$ was used to measure miRNA and target gene expression.

Table 1 The used primers for the gene expression of ROR $\gamma \mathrm{t}$, IL-17 and Let-7 isoforms in the spinal cord and splenocyte.

\section{Gene Primer}

\begin{tabular}{|l|ll}
\hline Beta-Actin & F & ATGCTCCCCGGGCTGTAT \\
& R & CATAGGAGTCCTTCTGACCCATTC \\
\hline ROR $\gamma \mathrm{t}$ & F & GCTACCAGAGGAAGTCAATGTG \\
& R & CTCCACACCACCGTATTTGC \\
& & \\
\hline IL-17 & F & AGCTTCATCTGTGTCTCTG \\
& R & TCTATCAGGGTCTTCATTGC \\
\hline MiR-98-5P & F & TGA GGT AGT AAG TTG TAT TGT T AA \\
& &
\end{tabular}




\section{Bioinformatic analyses}

microRNA sequences and annotations were obtained from the miRBase database. miRNA and Target Interactions were extracted from miRTarBase and TargetScan 7.2.

\section{Statistical Analysis}

Statistical analyses were performed using SPSS 20 and graphics were created with GraphPad Prism8. Statistical significance was determined by the two-way ANOVA followed by appropriate post hoc testing for multiple comparisons and Student's t test for two-group comparisons. Statistical significance was defined as a $\mathrm{P}$ value of less than 0.05 . The data is presented as a mean + standard error of the mean (SEM).

\section{Results}

\section{The effects of vitamin A, D and their combination on EAE disease severity}

Studies have shown that vitamins A, D and their analogs exert immune-regulatory roles in the context of autoimmune and chronic inflammatory diseases [50,51]. Previous works from our group and others have demonstrated that treatment of EAE mice with these two vitamins, alone or in combination, ameliorates EAE severity [52-58]. To reproduce previous results, we treated EAE mice with vitamin A (200 $\mu \mathrm{g} /$ mouse), vitamin D (100 $\mathrm{ng} /$ mouse) and a combination of two vitamins with half concentrations $(100 \mu \mathrm{g}+50 \mathrm{ng} /$ mouse). Vitamins were injected intraperitoneally, starting from day one before immunization. As shown in Fig.1A, vehicle-treated animals developed EAE symptoms at day 9 post-immunization, whereas vitamin $A$, vitamin $D$ and vitamin A+D-treated animals displayed disease symptoms between days 13 to 15 . There was no difference in disease onset between animals who had received the combination of vitamins, compared with those who had received vitamin A or D alone. Maximum clinical score (MCS) was $5.4 \pm 1.3$ for vehicle-treated EAE mice, $1.56 \pm 0.6$ for vitamin A-treated EAE mice, $0.78 \pm 0.2$ for vitamin Dtreated EAE, and $2.57 \pm 0.8$ in vitamin $A+D$ treated EAE groups (Fig. 1B). These results confirmed 
our previous findings with regards to the effects of vitamins A and D in mitigating disease severity in EAE animals.

\section{Vitamin D and A decrease the expression of IL17 in brain and the frequency of Th17 cells in spleen}

Various mechanisms have been proposed to underlie the protective effects of vitamins A and D in autoimmune diseases [54, 56-58]. Considering that MS/EAE pathogenic process is highly dependent on differentiation of CD4+ T cells to Th17 phenotype, we decided to explore the effects of vitamin A/D treatments on differentiation of T cells in the CNS as well as in peripheral immune system. We first evaluated the expression of Th17 signature cytokine, IL17, in spinal cord tissues obtained from EAE mice at day 30 post-immunization. Real-time PCR analysis of these tissues showed a significant increase in IL17 levels in spinal cords tissues of vehicle treated EAE mice compared with healthy controls (Fig. 2). However, mice treated with vitamin D showed a significant reduction in IL17 expression in spinal cord tissues. A non-significant decrease was also seen for mice that had received vitamin A or the combination of vitamins A and D (Fig. 2).

We next prepared splenocyte cultures from different groups of mice. Splenocytes were restimulated with $40 \mu \mathrm{g} / \mathrm{ml}$ of MOG, or with PMA/ionomycin before flow cytometry analysis for surface markers and intracellular IL-17 (Fig. 3).

Our analyses showed that vitamin A and vitamin D-treated mice had lower frequency of Th17 cells in their splenocytes, either in the absence or presence of in vitro MOG re-stimulation (Fig. 4). We also analyzed IL17 mRNA levels in splenocytes 24 and 48 hours after stimulation with 10 and $40 \mu \mathrm{g} / \mathrm{ml}$ of MOG antigen. Real-time RT-PCR showed significant downregulation of IL17 mRNA in cells stimulated with both MOG concentrations at 24 and 48 hour time-points (Fig. 5A and $\mathrm{B})$.

Measuring the expression of Th17-specific transcription factor, Ror- $\gamma$ (i.e., Rorc) revealed decreased levels of this transcription factor in vitamin A and D-treated animals, but this reached statistical significance only for $40 \mu \mathrm{g} / \mathrm{ml} \mathrm{MOG} \mathrm{concentration} \mathrm{at} 48$ hour time-point (Fig. 6A and B). Altogether, these data indicate that vitamin A and D treatment alone or in combination can influence development of Th17 cells, likely through suppression of transcription factors which mediate $\mathrm{T}$ cell differentiation. 


\section{Vitamin A and D alter the expression of miRNAs which target Ror- $\gamma$ in splenocytes}

Differentiation of $\mathrm{T}$ cells towards different phenotypes is regulated by a molecular machinery which connects extracellular signals to $\mathrm{T}$ cell gene expression program. Noncoding RNAs including microRNAs represent an important group of intracellular regulators of gene expression. MicroRNAs generally regulate gene expression by targeting the 3'UTR region of protein-coding genes, thereby suppressing their translation or degrading their transcripts $[59,60]$. To examine whether treatment of EAE mice with vitamin A and D had any effect on miRNAs which can potentially regulate Th17 differentiation, we searched miRNA-target database TargetScan for miRNAs which could target Ror- $\gamma$ transcripts. We focused on miRNA species that were broadly conserved among vertebrates with conserved binding sites between human and mouse Ror- $\gamma$. We found several miRNAs that met this criterion (Supp Table 1). Of these, miR-98-5p and let-7-5p were targeting a single miRNA-binding site at Ror- $\gamma$ 3'UTR (Fig. 7A).

Interestingly, our previous studies had shown that miR-98-5p is downregulated in the brain tissue of MS patients [61]. Moreover, miR-98-5p and let-7a-5p have been reported to regulate leukocyte function and inflammatory responses in different tissues [62-64]. We first examined the expression of miR-98-5p in RNA extracted from control and EAE mice spinal cords (Fig. 8A). Similar to previously reported findings in human tissues, miR-98-5p was downregulated in spinal cords of vehicle-treated EAE mice compared with healthy controls. Vitamin A and vitamin A+D-treated mice showed a significant upregulation of miR-98-5p. This phenomenon was not observed in vitamin D-treated mice (Fig. 8A). A similar expression pattern was also seen for let-7a-5p (Fig. 8B) .

We next asked whether miR-98-5p/Let-7-5p might also be altered in splenocytes obtained from vehicle or vitamin A/D-treated EAE mice. Analysis of miRNA expression in both control and MOG-stimulated splenocytes showed a significant increase in miR-98-5p levels in 24 and 48 hour time-points (Fig 9A and B). As for the combination of vitamin A and D, significant miR-98-5p upregulation could only be seen at 48 hour time point for cells stimulated with $40 \mu \mathrm{g} / \mathrm{ml}$ of antigen (Fig. 9B).

Increased levels of let-7-5p were also observed at 24 hours for vitamin A-treated animals $(10 \mu \mathrm{g} / \mathrm{ml}$ MOG) and vitamin D-treated animals (40 $\mu \mathrm{g} / \mathrm{ml} \mathrm{MOG}$ ) (Fig. 10A), and 48 hours for both vitamins (40 $\mu \mathrm{g} / \mathrm{ml} \mathrm{MOG})$. 
ROR $\gamma$ expression levels are inversely correlated with miR-98-5p and et-7a-5p levels in splenocytes

MicroRNAs regulate the expression of their target genes by translation inhibition or transcript degradation. We performed a correlation analysis between miR-98-5p and let-7a-5p and their target Ror- $\gamma$ in splenocytes derived from different groups of EAE mice. As shown in Fig. 11A, miR-98-5p showed a significant negative correlation with Ror- $\gamma$ at 24 hour time-point $(r=-0.58, p$ value $<0.05$ ). This inverse correlation was much stronger at 48 hour time-point (Fig. 11B, $r=-0.84$, $\mathrm{p}$ value $<0.001)$. For let7a-5p, we did not see a significant correlation with Ror- $\gamma$ at 24 hours (Fig.11C), but there was a significant negative correlation at 48 hours (Fig.11D, $\mathrm{r}=-0.69$, P value $<$ 0.01). It should be mentioned that negative correlation between the levels of miRNAs and their target mRNAs does not necessarily indicate a physical interaction; however, it can be considered as indirect evidence for the regulation of target mRNA by the miRNA species.

\section{Discussion}

Leukocyte differentiation is a critical step in immune response against pathogens, as well as in the pathophysiology of immune-related disorders. Among the cellular components of adaptive immune system, $\mathrm{T}$ cells and their differentiation into different phenotypes are key in developing protective and/or pathogenic immune reactions. In addition to genetic elements, environmental factors including micronutrients are known to influence the differentiation of these cells in physiological and pathological settings. In this study we examined the effects of vitamin A and D treatment of EAE mice on differentiation of Th17 cells, as well as the expression of miRNAs which could regulate this process. Our results showed that treatment with these vitamins could decrease EAE severity and diminish the frequency of Th17 cells. These effects were associated with upregulation of miRNAs which target Th17-specific Ror- $\gamma$ transcription factor.

Numerous studies have highlighted the importance of miRNAs in the regulation of $\mathrm{T}$ cell differentiation [65]. Indeed, microRNAs can target the molecular machinery that regulates $\mathrm{T}$ cell differentiation at different levels, including cell surface receptors, submembrane adaptor molecules, cytoplasmic signaling cascade, and transcription factors [37, 66, 67]. Considering that upstream signaling converges at the level of transcription factors, miRNAs that target these 
molecules are more critical in regulating cell development. Different transcription factors are known to control $\mathrm{T}$ helper cells differentiation, with Ror- $\gamma$ being the factor that regulates Th17 differentiation. This transcription factor is encoded by RORC gene and its homolog, Rorc, in human and mouse, respectively. RORC generates two RNA isoforms, the first isoform, Ror- $\gamma$, is expressed in many tissues including kidney, liver, thyroid and lung [68, 69]. The second isoform which is labeled Ror- $\gamma \mathrm{t}$, is mostly expressed in immune cells, including Th17 cells. In addition to these cells, Ror- $\gamma$ t is also expressed in innate lymphoid cells type 3 (ILC3) [70, 71]. The two isoforms are the result of different transcription start sites (TSS) and hence are distinguished by their 5' exons, while their 3' ends (and hence their 3' UTRs) are similar. Several miRNAs target this common 3' UTR region. In this study, we focused on miR-98-5p and let-7a-5p miRNAs. This selection was partly guided by the results of our former miRNA profiling studies that had shown downregulation of miR-98-5p in MS brain tissues, and also by the fact that both miRNAs belong to the let-7 family of miRNAs.

Let-7 family of miRNAs include numerous miRNAs including miR-98 and Let-7a subfamilies, which were evaluated in the current study. Human mir-98 (i.e., hsa-mir-98) gene is located on the short arm of chromosome X. This gene is located inside one of the introns of the HUWE1 gene and is transcribed from the same DNA strand as the host gene. After transcription, it generates two isoforms; hsa-miR-98-5p, which is the dominant isoform, and miR-98-3p, which is the minor isoform. A similar situation exists for mouse miR-98 (i.e., mmu-mir-98); its gene is located inside murine Huwe 1 gene on chromosome $X$ and it generates a $5 p$ dominant and a $3 p$ minor isoform. MiR-98 stem-loop sequence is highly conserved between human and mouse; indeed, human and mouse mature miR-98-5p isoforms are identical. Studies on the role of miR-98-5p in immune system have shown predominantly anti-inflammatory effects for this miRNA. Yuan et al have reported that miR-98-5p is down-regulated in the PBMCs of SLE patients and it can target IL-6 mRNA directly. They also showed the miR-98-5p inhibitors could enhance the production of inflammatory cytokines by PBMCs [72]. Peng et al have demonstrated that miR-98-5p can block the differentiation of macrophages to M2 phenotype by targeting Trib1 and silencing miR-98-5p can decrease disease severity in a model of colitis; which indicates a pro-inflammatory role of this miRNA [73]. Another study has pointed to anti-inflammatory effects for miR-98-5p by targeting VCAM-1 [73]. Several studies have also pointed to protective and anti-inflammatory effects of miR-98-5p in the context of neuroinflammatory disorders. Rom et al have illustrated that miR-98- 
$5 \mathrm{p}$ decreases inflammation and protects blood brain barrier (BBB) permeability in neuroinflammatory conditions by targeting CCL2 and CCL5 chemokines [74]. Likewise, miR-98$5 p$ exerts protective effects in animal models of stroke, an effect which is mediated by decreased infiltration of proinflammatory leukocytes into the brain as well as diminished differentiation of microglia to the M1 phenotype [75]. Moreover, miR-98-5p is known to reduce neuroinflammation in a model of peripheral nerve injury; this is caused by targeting STAT3 and HMGA2 and reducing the levels of inflammatory cytokines, TNF- $\alpha$, IL-1 and IL-6 [76, 77]. As alluded to before, in our previous studies we had detected decreased levels of miR-98-5p is brain tissues from MS patients [61]. In the current study, we found that miR-98-5p levels were diminished in the spinal cords of EAE mice compared with healthy controls and that it was negatively correlated with Ror- $\gamma t$ levels. Treatment with vitamin A and D did increase miR-98-5p levels in spinal cord tissue. These data, together with previous findings by other groups point to anti-inflammatory and protective roles for miR-98-p in MS/EAE and that this can partly explain the protective effect of vitamins A and D in inflammatory diseases.

Human let-7a miRNAs are transcribed from three orthologous genes, let-7a1, let-7a2 and let-7a3, which are located on the long arms of chromosomes 9, 11 and 22, respectively. All three genes produce the same mature let-7-5p sequence. These miRNAs have widespread expression in different tissues. Within the immune system, let-7 miRNAs are expressed in lymphocytes and macrophages and influence the differentiation of these cells [78-80]. Jiang et al have shown that Let-7 can suppress the activation of B cells by targeting proteins involved in glucose and glutamine utilization [79]. Let-7 miRNAs are also required for $\mathrm{T}$ cell survival [80]. In the context of neuroinflammation, let-7 miRNAs are known to negatively regulate differentiation of pathogenic Th17 cells [81]. Th17 differentiation requires signals by extracellular cytokines including IL23. IL23 receptor mRNA has been shown to have potential let-7f binding sites [82]. In the current study, we observed suppression of let-7a-5p following EAE induction and its increase following vitamin $\mathrm{A}$ and $\mathrm{D}$ treatment. Of note, vitamin $\mathrm{D}$ has been shown to increase let-7a-2 expression through interaction with VDRE, which is located in the pre-let-7a-2 gene promoter [83].

Identification of environmental factors which can influence the development of autoimmune diseases is crucial for devising preventive and therapeutic strategies. In addition to identification of these factors, elucidating mechanisms by which they exert their effects can be of value from 
pathogenesis and therapy perspectives. Results of the current study indicated that vitamins A and D likely mediate their protective effects in EAE through increased expression of miRNAs that target a Th17-specific transcription factor. That said, micronutrients can influence varieties of disease-related mechanisms, both at the level of immune system and repair mechanisms inside the CNS. Further investigations, including immune profiling studies on human subjects will be required to better unravel the underlying processes that are influenced by these compounds. 


\section{Acknowledgments}

The authors would like to thank the faculty members at Department of Immunology at School of Public Health at TUMS for helpful discussions. This work supported by research grants from the National Institute for Medical Research Development (NIMAD, grant No:977636) and Tehran University of Medical Sciences (TUMS, grant No. 97-02-27 38998). 


\section{Fig Legends:}

Figu.1 Comparison of clinical scores of EAE between vitamins-treated and vehicle-treated. A EAE clinical scores were recorded daily after immunization with MOG in different groups including vehicle-treated, vitamin A, D, and A+D -treated animals. B Maximum clinical scores were also calculated in different groups (b). Values are presented as mean $\pm \mathrm{SEM}, * \mathrm{p}<0.05$, ** $\mathrm{p}<0.01, * * * \mathrm{p}<0.001$, one-way ANOVA with Tukey post hoc.

Fig. 2 IL-17 mRNA expression in the spinal cord tissues in vehicle-treated and vitamin-treated EAE groups. Values are presented as mean \pm SEM; eight mice per group, ${ }^{*} \mathrm{p}<0.05, * * \mathrm{p}<0.01$, *** $\mathrm{p}<0.001$, one-way ANOVA, Tukey post hoc

Fig. 3 Gating strategy used to quantify the numbers of Th17 cells in splenocyte cultures.

Fig.4 Effect of different on the frequency of Th17 cells in MOG and/or PMA/ionomycinstimulated splenocytes. Data are shown as mean $\pm \mathrm{SEM}, \mathrm{n}=8$. Values are presented as mean \pm SEM, $* \mathrm{p}<0.05, * * \mathrm{p}<0.01, * * * \mathrm{p}<0.001$, Two-way ANOVA, Tukey post hoc.

Fig. 5 IL-17 expression levels in splenocytes. A IL-17 expression levels in MOG-stimulated splenocytes obtained from different groups. Splenocytes were stimulated with 0 (control), 10, 40 $\mu \mathrm{g} / \mathrm{ml}$ of MOG peptide for $24 \mathrm{~h}$ and B $48 \mathrm{~h}$. Values are presented as mean $\pm \mathrm{SEM}$, eight mice in each group, $* \mathrm{p}<0.05, * * \mathrm{p}<0.01, * * * \mathrm{p}<0.001$, Two-way ANOVA, Tukey post hoc.

Fig. 6 ROR $\gamma$ t expression levels in splenocytes. A ROR $\gamma \mathrm{t}$ expression levels in MOG-stimulated splenocytes obtained from different groups. Splenocytes were stimulated with $0,10,40 \mu \mathrm{g} / \mathrm{ml}$ of MOG peptide for $24 \mathrm{~h}$ and $\mathbf{B} 48 \mathrm{~h}$. Values are presented as mean \pm SEM, eight mice in each group, $* \mathrm{p}<0.05, * * \mathrm{p}<0.01, * * * \mathrm{p}<0.001$, Two-way ANOVA, Tukey post hoc.

Fig. 7 Potentially targeting miRNA in CNS and splenocyte of mice. A Predicted target sites for miR-98-5p and Let-7a-5p on ROR $\gamma \mathrm{t}$ mRNA $3^{\prime}$ UTR according to TargetScan algorithm. B Homology between human and mouse mature miRNA sequences. C Sequence of predicted binding sites for miR-98-5p and Let-7a-5p on $3^{\prime} \quad$ UTR of mouse ROR $\gamma t$ mRNA.

Fig. 8 Expression levels of miRNAs in the spinal cords of different EAE groups. A The expression level of miR-98-5P and B Let-7-5P are shown as bar graphs. Values are shown as mean \pm SEM, eight mice in each group, $* \mathrm{p}<0.05, * * \mathrm{p}<0.01, * * * \mathrm{p}<0.001$, one-way ANOVA, Tukey post hoc. 
Fig. 9 Expression levels of miR-98-5p in MOG-stimulated splenocytes obtained from different groups of animals. A splenocytes Splenocytes were stimulated with 0 (control), 10, $40 \mu \mathrm{g} / \mathrm{ml}$ of MOG peptide for $24 \mathrm{~h}$ and $\mathbf{B} 48 \mathrm{~h}$. Data are shown as mean \pm SEM, $\mathrm{n}=8$. The values were presented as mean \pm SEM, eight mice in each group, ${ }^{*} \mathrm{p}<0.05,{ }^{*} \mathrm{p}<0.01, * * * \mathrm{p}<0.001$, Two-way ANOVA, Tukey post hoc

Fig. 10 Expression levels of Let-7a-5p in MOG-stimulated splenocytes obtained from different groups of animals. A Splenocytes were stimulated with 0 (control), 10, $40 \mu \mathrm{g} / \mathrm{ml}$ of MOG peptide for $24 \mathrm{~h}$ and $\mathbf{B} 48 \mathrm{~h}$. Data are shown as mean \pm SEM, eight mice in each group, * $\mathrm{p}<0.05$, ** $\mathrm{p}<0.01, * * * \mathrm{p}<0.001$, Two-way ANOVA, Tukey post hoc.

Fig. 11 Correlation analysis between ROR $\gamma$ mRNA and miRNAs. A Dot plot demonstrates the correlation between ROR $\gamma$ mRNA and miR-98-5p in splenocytes $24 \mathrm{~h}$ and $\mathbf{B} 48 \mathrm{~h}$ after stimulation with MOG peptide. C Likewise, correlation between ROR $\gamma$ mRNA and let-7a-5p after $24 \mathrm{~h}$ and $\mathbf{D}$ $48 \mathrm{~h}$ of stimulation are shown. (Pearson correlation; *p $<0.05, * * \mathrm{p}<0.01$ ). 


\section{References}

1 Sospedra M, Martin R (2005) Immunology of multiple sclerosis. Annu. Rev. Immunol. 23: 683747

2 Hemmer B, Archelos JJ, Hartung HP (2002) New concepts in the immunopathogenesis of multiple sclerosis. Nat Rev Neurosci 3: 291-301

3 Prat A, Antel J (2005) Pathogenesis of multiple sclerosis. Curr Opin Neurol 18: 225-230

4 Jadidi-Niaragh F, Mirshafiey A (2011) Th17 cell, the new player of neuroinflammatory process in multiple sclerosis. Scand J Immunol 74: 1-13

5 Moser T, Akgun K, Proschmann U, Sellner J, Ziemssen T (2020) The role of TH17 cells in multiple sclerosis: Therapeutic implications. Autoimmun Rev 19: 102647

6 Gallucci M, Bozzao A, Splendiani A, Masciocchi C, Passariello R (1990) Wernicke encephalopathy: MR findings in five patients. AJR Am J Roentgenol 155: 1309-1314

7 Kebir H, Kreymborg K, Ifergan I, Dodelet-Devillers A, Cayrol R, Bernard M, Giuliani F, Arbour N, Becher B, Prat A (2007) Human TH 17 lymphocytes promote blood-brain barrier disruption and central nervous system inflammation. Nature medicine 13: 1173-1175

8 Larochelle C, Wasser B, Jamann H, Loffel JT, Cui QL, Tastet O, Schillner M, Luchtman D, Birkenstock J, Stroh A et al (2021) Pro-inflammatory T helper 17 directly harms oligodendrocytes in neuroinflammation. Proc Natl Acad Sci U S A 118

9 Liu M, Hu X, Wang Y, Peng F, Yang Y, Chen X, Lu Z, Zheng X (2009) Effect of high-dose methylprednisolone treatment on Th17 cells in patients with multiple sclerosis in relapse. Acta Neurol Scand 120: 235-241

10 Ramgolam VS, Markovic-Plese S (2010) Interferon-beta inhibits Th17 cell differentiation in patients with multiple sclerosis. Endocr Metab Immune Disord Drug Targets 10: 161-167

11 Mehling M, Lindberg R, Raulf F, Kuhle J, Hess C, Kappos L, Brinkmann V (2010) Th17 central memory T cells are reduced by FTY720 in patients with multiple sclerosis. Neurology 75: 403-410

12 Sweeney CM, Lonergan R, Basdeo SA, Kinsella K, Dungan LS, Higgins SC, Kelly PJ, Costelloe L, Tubridy N, Mills KH et al (2011) IL-27 mediates the response to IFN-beta therapy in multiple sclerosis patients by inhibiting Th17 cells. Brain Behav Immun 25: 1170-1181

13 Darlington PJ, Touil T, Doucet JS, Gaucher D, Zeidan J, Gauchat D, Corsini R, Kim HJ, Duddy M, Jalili F et al (2013) Diminished Th17 (not Th1) responses underlie multiple sclerosis disease abrogation after hematopoietic stem cell transplantation. Ann Neurol 73: 341-354

14 Sato DK, Nakashima I, Bar-Or A, Misu T, Suzuki C, Nishiyama S, Kuroda H, Fujihara K, Aoki M (2014) Changes in Th17 and regulatory T cells after fingolimod initiation to treat multiple sclerosis. J Neuroimmunol 268: 95-98

15 Oksenberg JR, Baranzini SE, Sawcer S, Hauser SL (2008) The genetics of multiple sclerosis: SNPs to pathways to pathogenesis. Nat Rev Genet 9: 516-526

16 Handel AE, Giovannoni G, Ebers GC, Ramagopalan SV (2010) Environmental factors and their timing in adult-onset multiple sclerosis. Nat Rev Neurol 6: 156-166

17 Junker A, Hohlfeld R, Meinl E (2011) The emerging role of microRNAs in multiple sclerosis. Nat Rev Neurol 7: 56-59

18 Koch MW, Metz LM, Kovalchuk O (2013) Epigenetic changes in patients with multiple sclerosis. Nat Rev Neurol 9: 35-43

19 Schwarz S, Leweling H (2005) Multiple sclerosis and nutrition. Mult Scler 11: 24-32

20 Riccio P, Rossano R (2015) Nutrition facts in multiple sclerosis. ASN Neuro 7 
Evans E, Levasseur V, Cross AH, Piccio L (2019) An overview of the current state of evidence for the role of specific diets in multiple sclerosis. Mult Scler Relat Disord 36: 101393 von Geldern G, Mowry EM (2012) The influence of nutritional factors on the prognosis of multiple sclerosis. Nat Rev Neurol 8: 678-689

23 Yeh WZ, Gresle M, Jokubaitis V, Stankovich J, van der Walt A, Butzkueven H (2020) Immunoregulatory effects and therapeutic potential of vitamin $\mathrm{D}$ in multiple sclerosis. $\mathrm{Br} \mathrm{J}$ Pharmacol 177: 4113-4133 Sintzel MB, Rametta M, Reder AT (2018) Vitamin D and Multiple Sclerosis: A Comprehensive Review. Neurol Ther 7: 59-85 Fragoso YD, Stoney PN, McCaffery PJ (2014) The evidence for a beneficial role of vitamin A in multiple sclerosis. CNS Drugs 28: 291-299 Evans E, Piccio L, Cross AH (2018) Use of Vitamins and Dietary Supplements by Patients With Multiple Sclerosis: A Review. JAMA Neurol 75: 1013-1021 Mohammadi-Kordkhayli M, Ahangar-Parvin R, Azizi SV, Nemati M, Shamsizadeh A, Khaksari M, Moazzeni SM, Jafarzadeh A (2015) Vitamin D Modulates the Expression of IL-27 and IL-33 in the Central Nervous System in Experimental Autoimmune Encephalomyelitis. Iranian Journal of Immunology 12: 35-49

28 Skrobot A, Demkow U, Wachowska M (2018) Immunomodulatory role of vitamin D: a review. Current Trends in Immunity and Respiratory Infections: 13-23

Abdolahi M, Yavari P, Honarvar NM, Bitarafan S, Mahmoudi M, Saboor-Yaraghi AA (2015) Molecular mechanisms of the action of vitamin A in Th17/Treg axis in multiple sclerosis. Journal of Molecular Neuroscience 57: 605-613

Elias KM, Laurence A, Davidson TS, Stephens G, Kanno Y, Shevach EM, O'Shea JJ (2008) Retinoic acid inhibits Th17 polarization and enhances FoxP3 expression through a Stat-3/Stat-5 independent signaling pathway. Blood, The Journal of the American Society of Hematology 111: 1013-1020

31 Massacesi L, Abbamondi AL, Giorgi C, Sarlo F, Lolli F, Amaducci L (1987) Suppression of experimental allergic encephalomyelitis by retinoic acid. Journal of the neurological sciences 80: $55-64$

32 Lu TX, Rothenberg ME (2018) MicroRNA. Journal of Allergy and Clinical Immunology 141: 12021207

33 O'Connell RM, Rao DS, Chaudhuri AA, Baltimore D (2010) Physiological and pathological roles for microRNAs in the immune system. Nat Rev Immunol 10: 111-122

34 Mehta A, Baltimore D (2016) MicroRNAs as regulatory elements in immune system logic. Nat Rev Immunol 16: 279-294

35 Bushati N, Cohen SM (2007) microRNA functions. Annu. Rev. Cell Dev. Biol. 23: 175-205

36 Liu C, Yang H, Shi W, Wang T, Ruan Q (2018) MicroRNA-mediated regulation of T helper type 17/regulatory T-cell balance in autoimmune disease. Immunology 155: 427-434

37 Jeker LT, Bluestone JA (2013) MicroRNA regulation of T-cell differentiation and function. Immunol Rev 253: 65-81

38 Kunze-Schumacher H, Krueger A (2020) The Role of MicroRNAs in Development and Function of Regulatory T Cells - Lessons for a Better Understanding of MicroRNA Biology. Front Immunol 11: 2185

39 Maul J, Alterauge D, Baumjohann D (2019) MicroRNA-mediated regulation of T follicular helper and T follicular regulatory cell identity. Immunol Rev 288: 97-111

40 Simpson LJ, Ansel KM (2015) MicroRNA regulation of lymphocyte tolerance and autoimmunity. J Clin Invest 125: 2242-2249 

misexpression in cancer and autoimmune diseases: a critical review. Clin Rev Allergy Immunol 47: 128-135

42 Zhu S, Pan W, Qian Y (2013) MicroRNA in immunity and autoimmunity. J Mol Med (Berl) 91: 1039-1050

43 Chen C, Zhou Y, Wang J, Yan Y, Peng L, Qiu W (2018) Dysregulated MicroRNA Involvement in Multiple Sclerosis by Induction of T Helper 17 Cell Differentiation. Front Immunol 9: 1256 Du C, Liu C, Kang J, Zhao G, Ye Z, Huang S, Li Z, Wu Z, Pei G (2009) MicroRNA miR-326 regulates $\mathrm{TH}-17$ differentiation and is associated with the pathogenesis of multiple sclerosis. Nat Immunol 10: $1252-1259$ 181 Variants Regulate T Cell Phenotype in the Context of Autoimmune Neuroinflammation. Front Immunol 8: 758 MicroRNA-92a Drives Th1 Responses in the Experimental Autoimmune Encephalomyelitis. Inflammation 42: 235-245

47 Talebi F, Ghorbani S, Chan WF, Boghozian R, Masoumi F, Ghasemi S, Vojgani M, Power C, Noorbakhsh F (2017) MicroRNA-142 regulates inflammation and T cell differentiation in an animal model of multiple sclerosis. J Neuroinflammation 14: 55

48 Junker A, Krumbholz M, Eisele S, Mohan H, Augstein F, Bittner R, Lassmann $\mathrm{H}$, Wekerle $\mathrm{H}$, Hohlfeld R, Meinl E (2009) MicroRNA profiling of multiple sclerosis lesions identifies modulators of the regulatory protein CD47. Brain 132: 3342-3352

49 Giuliani F, Metz LM, Wilson T, Fan Y, Bar-Or A, Yong VW (2005) Additive effect of the combination of glatiramer acetate and minocycline in a model of MS. J Neuroimmunol 158: 213221

50 Griffin MD, Xing N, Kumar R (2003) Vitamin D and its analogs as regulators of immune activation and antigen presentation. Annu Rev Nutr 23: 117-145

51 Mora JR, Iwata M, von Andrian UH (2008) Vitamin effects on the immune system: vitamins A and D take centre stage. Nat Rev Immunol 8: 685-698

52 Parastouei K, Solaymani-Mohammadi F, Shiri-Shahsavar MR, Chahardoli R, Nasl-Khameneh AM, Zarandi MB, Ghotloo S, Saboor-Yaraghi AA (2020) The effect of calcitriol and all-trans retinoic acid on T-bet, IFN- $\gamma$, GATA3 and IL-4 genes expression in experimental autoimmune encephalomyelitis. Apmis 128: 583-592

53 Raverdeau M, Christofi M, Malara A, Wilk MM, Misiak A, Kuffova L, Yu T, McGinley AM, Quinn SM, Massilamany $C$ et al (2019) Retinoic acid-induced autoantigen-specific type 1 regulatory $T$ cells suppress autoimmunity. EMBO Rep 20

54 Zhan XX, Liu Y, Yang JF, Wang GY, Mu L, Zhang TS, Xie XL, Wang JH, Liu YM, Kong QF et al (2013) All-trans-retinoic acid ameliorates experimental allergic encephalomyelitis by affecting dendritic cell and monocyte development. Immunology 138: 333-345

55 Mimura LAN, Fraga-Silva TFC, Oliveira LRC, Ishikawa LLW, Borim PA, Machado CM, Junior J, Fonseca DMD, Sartori A (2021) Preclinical Therapy with Vitamin D3 in Experimental Encephalomyelitis: Efficacy and Comparison with Paricalcitol. Int J Mol Sci 22

56 Spanier JA, Nashold FE, Nelson CD, Praska CE, Hayes CE (2020) Vitamin D3-mediated resistance to a multiple sclerosis model disease depends on myeloid cell 1,25-dihydroxyvitamin D3 synthesis and correlates with increased CD4(+) T cell CTLA-4 expression. J Neuroimmunol 338: 577105

57 Cao Q, Zheng C, Xie Z, Liu L, Zhu J, Jin T (2020) The change of PD1, PDL1 in experimental autoimmune encephalomyelitis treated by 1,25(OH)2D3. J Neuroimmunol 338: 577079 
Moore JR, Hubler SL, Nelson CD, Nashold FE, Spanier JA, Hayes CE (2018) 1,25-Dihydroxyvitamin D3 increases the methionine cycle, CD4(+) T cell DNA methylation and Helios(+)Foxp3(+) T regulatory cells to reverse autoimmune neurodegenerative disease. J Neuroimmunol 324: 100114 Lindsay MA (2008) microRNAs and the immune response. Trends Immunol 29: 343-351 Brodersen P, Voinnet O (2009) Revisiting the principles of microRNA target recognition and mode of action. Nat Rev Mol Cell Biol 10: 141-148

61 Noorbakhsh F, Ellestad KK, Maingat F, Warren KG, Han MH, Steinman L, Baker GB, Power C (2011) Impaired neurosteroid synthesis in multiple sclerosis. Brain 134: 2703-2721 Parker MI, Palladino MA (2017) MicroRNAs downregulated following immune activation of rat testis. Am J Reprod Immunol 77

63 Peng $Y$, Wang $Q$, Yang W, Yang Q, Pei Y, Zhang W (2020) MiR-98-5p expression inhibits polarization of macrophages to an M2 phenotype by targeting Trib1 in inflammatory bowel disease. Acta Biochim Pol 67: 157-163 Zhang J, Han L, Chen F (2021) Let-7a-5p regulates the inflammatory response in chronic rhinosinusitis with nasal polyps. Diagn Pathol 16: 27 Baumjohann D, Ansel KM (2013) MicroRNA-mediated regulation of T helper cell differentiation and plasticity. Nature Reviews Immunology 13: 666-678 Rodriguez-Galan A, Fernandez-Messina L, Sanchez-Madrid F (2018) Control of Immunoregulatory Molecules by miRNAs in T Cell Activation. Front Immunol 9: 2148 Fu G, Rybakin V, Brzostek J, Paster W, Acuto O, Gascoigne NR (2014) Fine-tuning T cell receptor signaling to control T cell development. Trends Immunol 35: 311-318 Fagerberg L, Hallstrom BM, Oksvold P, Kampf C, Djureinovic D, Odeberg J, Habuka M, Tahmasebpoor S, Danielsson A, Edlund K et al (2014) Analysis of the human tissue-specific expression by genome-wide integration of transcriptomics and antibody-based proteomics. Mol Cell Proteomics 13: 397-406

69 Medvedev A, Chistokhina A, Hirose T, Jetten AM (1997) Genomic structure and chromosomal mapping of the nuclear orphan receptor ROR gamma (RORC) gene. Genomics 46: 93-102

70 Villey I, de Chasseval R, de Villartay JP (1999) RORgammaT, a thymus-specific isoform of the orphan nuclear receptor RORgamma / TOR, is up-regulated by signaling through the pre-T cell receptor and binds to the TEA promoter. Eur J Immunol 29: 4072-4080

71 Eberl G, Littman DR (2003) The role of the nuclear hormone receptor RORgammat in the development of lymph nodes and Peyer's patches. Immunol Rev 195: 81-90 Yuan S, Tang C, Chen D, Li F, Huang M, Ye J, He Z, Li W, Chen Y, Lin X et al (2019) miR-98 Modulates Cytokine Production from Human PBMCs in Systemic Lupus Erythematosus by Targeting IL-6 mRNA. J Immunol Res 2019: 9827574

73 Peng $Y$, Wang $Q$, Yang W, Yang Q, Pei Y, Zhang W (2020) MiR-98-5p expression inhibits polarization of macrophages to an M2 phenotype by targeting Trib1 in inflammatory bowel disease. Acta Biochimica Polonica 67: 157-163

74 Rom S, Dykstra H, Zuluaga-Ramirez V, Reichenbach NL, Persidsky Y (2015) miR-98 and let-7g* protect the blood-brain barrier under neuroinflammatory conditions. Journal of Cerebral Blood Flow \& Metabolism 35: 1957-1965

75 Bernstein DL, Zuluaga-Ramirez V, Gajghate S, Reichenbach NL, Polyak B, Persidsky Y, Rom S (2020) miR-98 reduces endothelial dysfunction by protecting blood-brain barrier (BBB) and improves neurological outcomes in mouse ischemia/reperfusion stroke model. Journal of Cerebral Blood Flow \& Metabolism 40: 1953-1965

76 Zhong L, Fu K, Xiao W, Wang F, Shen LL (2018) Overexpression of miR-98 attenuates neuropathic pain development via targeting STAT3 in CCI rat models. J Cell Biochem 
77 Zhang Y, Su Z, An LJ, Li L, Wei M, Ge DJ, Liu HL (2019) miR-98 acts as an inhibitor in chronic constriction injury-induced neuropathic pain via downregulation of high-mobility group AT-hook 2. J Cell Biochem 120: 10363-10369

78 Banerjee S, Xie N, Cui H, Tan Z, Yang S, Icyuz M, Abraham E, Liu G (2013) MicroRNA let-7c regulates macrophage polarization. The Journal of immunology 190: 6542-6549

79 Jiang S, Yan W, Wang SE, Baltimore D (2018) Let-7 suppresses B cell activation through restricting the availability of necessary nutrients. Cell metabolism 27: 393-403. e394

80 Pobezinskaya EL, Wells AC, Angelou CC, Fagerberg E, Aral E, Iverson E, Kimura MY, Pobezinsky LA (2019) Survival of naïve T cells requires the expression of let-7 miRNAs. Frontiers in immunology 10: 955

81 Angelou CC, Wells AC, Vijayaraghavan J, Dougan CE, Lawlor R, Iverson E, Lazarevic V, Kimura MY, Peyton SR, Minter LM (2020) Differentiation of pathogenic Th17 cells is negatively regulated by Let-7 microRNAs in a mouse model of multiple sclerosis. Frontiers in immunology 10: 3125

82 Li Z, Wu F, Brant SR, Kwon JH (2011) IL-23 receptor regulation by Let-7f in human CD4+ memory T cells. The Journal of Immunology 186: 6182-6190

83 Guan H, Liu C, Chen Z, Wang L, Li C, Zhao J, Yu Y, Zhang P, Chen W, Jiang A (2013) 1, 25Dihydroxyvitamin D3 up-regulates expression of hsa-let-7a-2 through the interaction of VDR/VDRE in human lung cancer A549 cells. Gene 522: 142-146 


\section{Statements and Declaration}

\section{Funding}

This work supported by research grants from the National Institute for Medical Research Development (NIMAD, grant No:977636) and Tehran University of Medical Sciences (TUMS, grant No. 97-02-27 38998) and Dr Ali akbar Saboor-Yaraghi has received research support from TUMS and NIMAD. The authors declare that no funds, grants, or other support were received during the preparation of this manuscript.

\section{Competing Interests}

Competing Interests Marziyeh Mohammadi as a first author and $\mathrm{PhD}$ student and this article is her $\mathrm{PhD}$ project, has received financial from Tehran university of medical sciences. and Samira Ghorbani and Farideh Talebi have no financial interests. Fatemeh Mansouri as laboratory expert has received financial from Tehran university of medical sciences. Dr Farshid Noorbakhsh, Dr Ali akbar Saboor Yaraghi and Dr Mohammad ali Sahraian as supervisor and adviser have received research funding from Tehran university of medical sciences

\section{Author Contributions}

All authors contributed to the study conception and design. Material preparation, data collection and analysis were performed by [Marziyeh Mohammadi kordkhayli and Farideh Talebi], [Marziyeh Mohammadi kordkhayli and Fatemeh Mansouri and Samira Ghorbani] and [Marziyeh Mohammadi kordkhayli and Dr Mohamadi ali Sahraian, as adviser]. The first draft of the manuscript was written by [Marziyeh Mohammadi kordkhayli] and manuscript edited and designed study by [ Dr Farshid Noorbakhsh and Dr Aliakbar Saboor Yaraghi] as a supervisor and all authors commented on previous versions of the manuscript. All authors read and approved the final manuscript." 


\section{Ethics approval}

All experiments of this study (The effect of vitamin D and A on the expression level of microRNA involve in the differentiation of Tcell and the prevention of inflammatory process in the EAE model) and animal care methods were approved by the Ethics Committee on Animal Experimentation of Tehran University of Medical Sciences.

(Approval date: 2018-07-18)

(No: IR.TUMS.SPH.REC.1397.091)

\section{Consent to publish}

Consent to publish "The authors state that no human samples were used in this study, and that all samples were obtained from animals such as mice.”. 
A

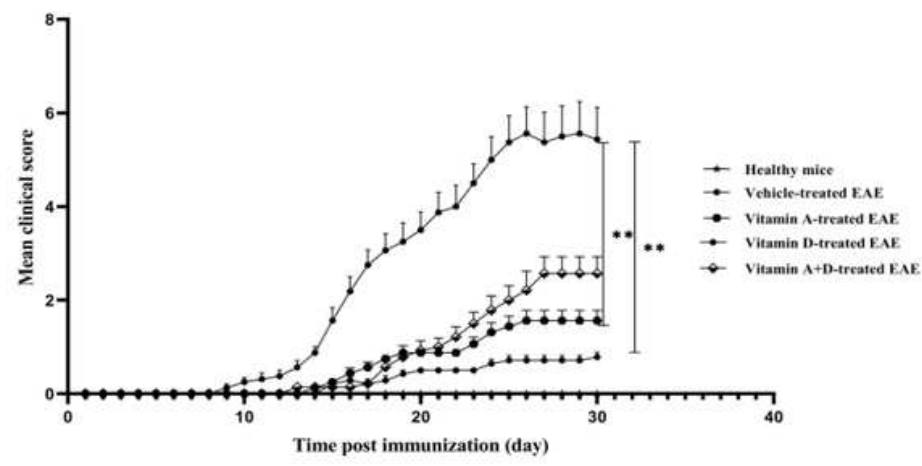

B

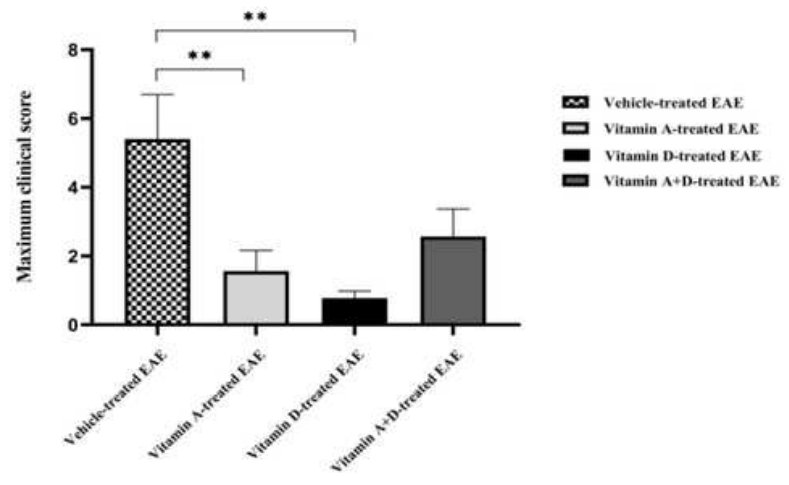

Figure 1

Comparison of clinical scores of EAE between vitamins-treated and vehicle-treated. A EAE clinical scores were recorded daily after immunization with $M O G$ in different groups including vehicle-treated, vitamin $A$, $D$, and A+D -treated animals. B Maximum clinical scores were also calculated in different groups (b). Values are presented as mean \pm SEM, * $p<0.05, * \star p<0.01, * \star \star p<0.001$, one-way ANOVA with Tukey post hoc.

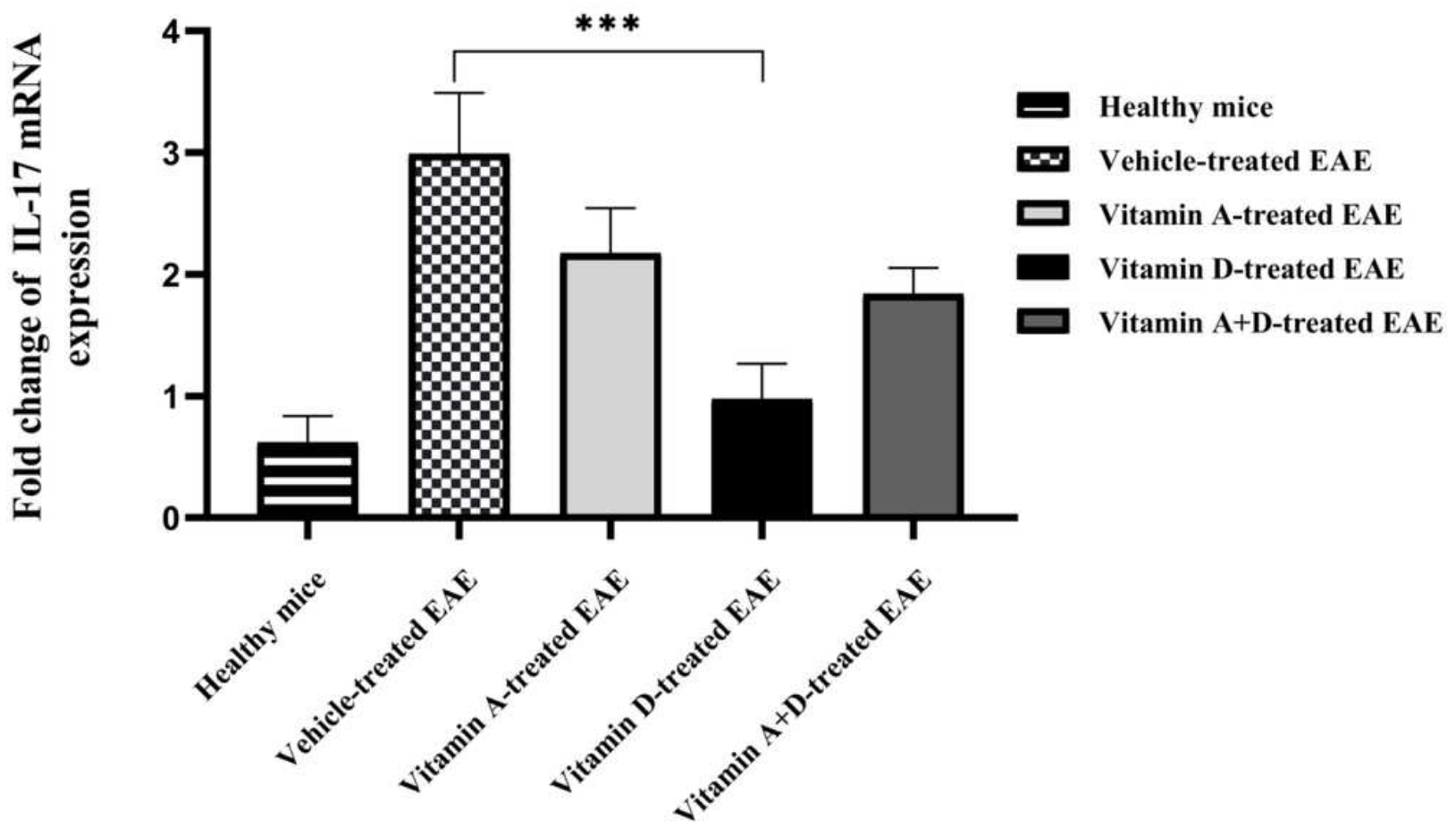


Figure 2

IL-17 mRNA expression in the spinal cord tissues in vehicle-treated and vitamin-treated EAE groups. Values are presented as mean \pm SEM; eight mice per group, ${ }^{*} p<0.05,{ }^{* \star} p<0.01$, ${ }^{\star \star \star} p<0.001$, one-way ANOVA, Tukey post hoc
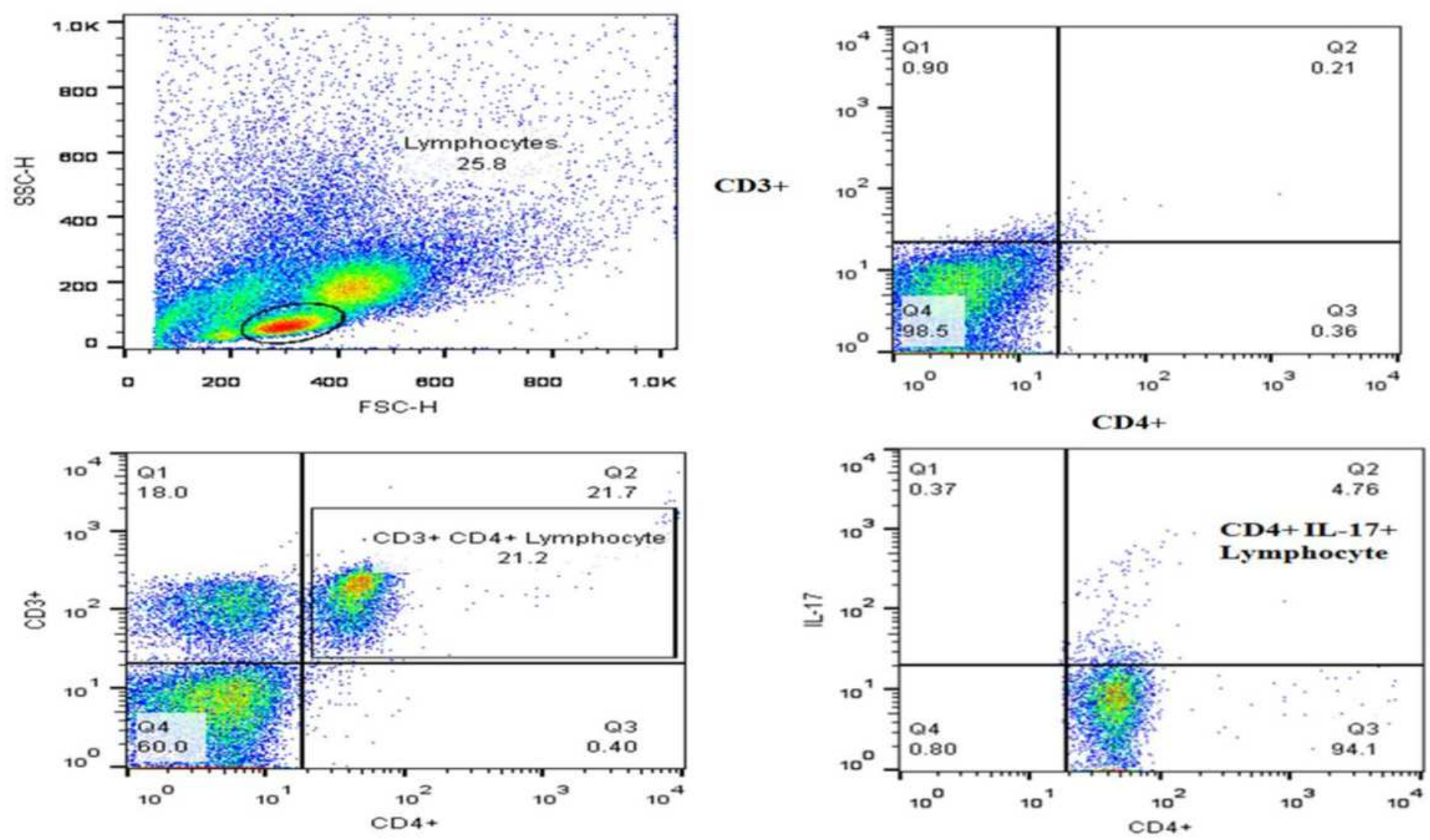

Figure 3

Gating strategy used to quantify the numbers of Th17 cells in splenocyte cultures.
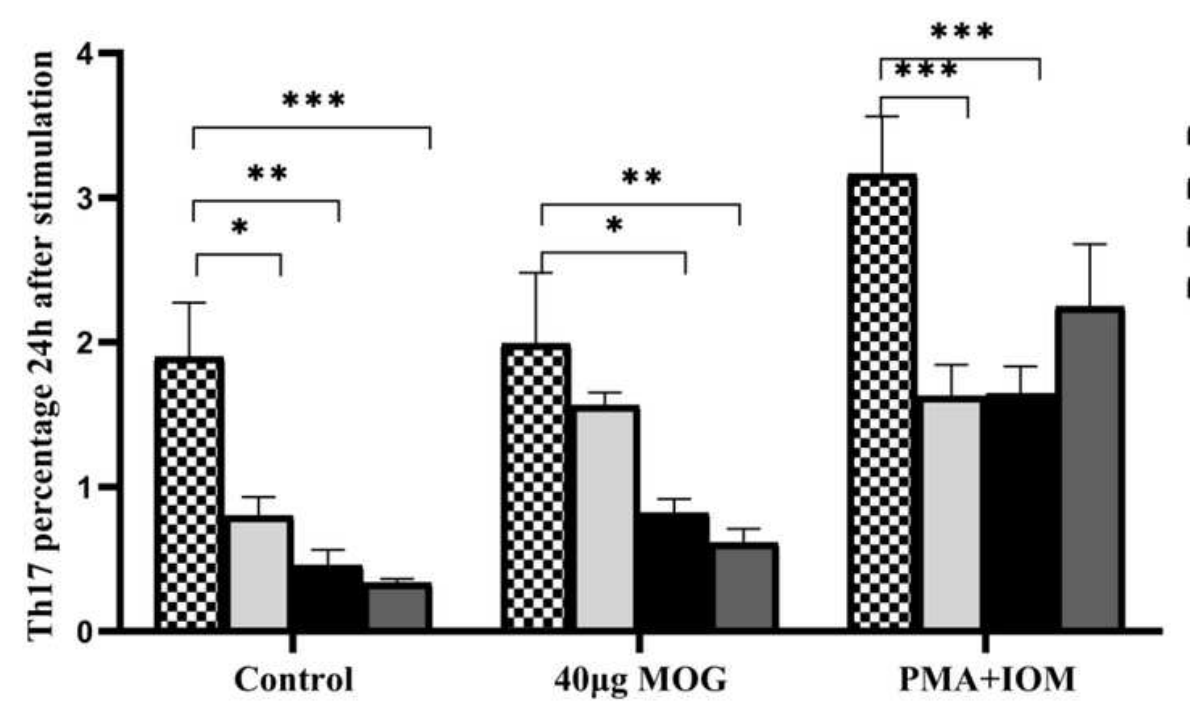

-- Vehicle-treated EAE

Vitamin A-treated EAE

Vitamin D-treated EAE

Vitamin A+D-treated EAE 
Figure 4

Effect of different on the frequency of Th17 cells in MOG and/or PMA/ionomycin-stimulated splenocytes. Data are shown as mean $\pm S E M, n=8$. Values are presented as mean $\pm S E M, * p<0.05, * \star p<0.01, * \star \star$ $\mathrm{p}<0.001$, Two-way ANOVA, Tukey post hoc.

A

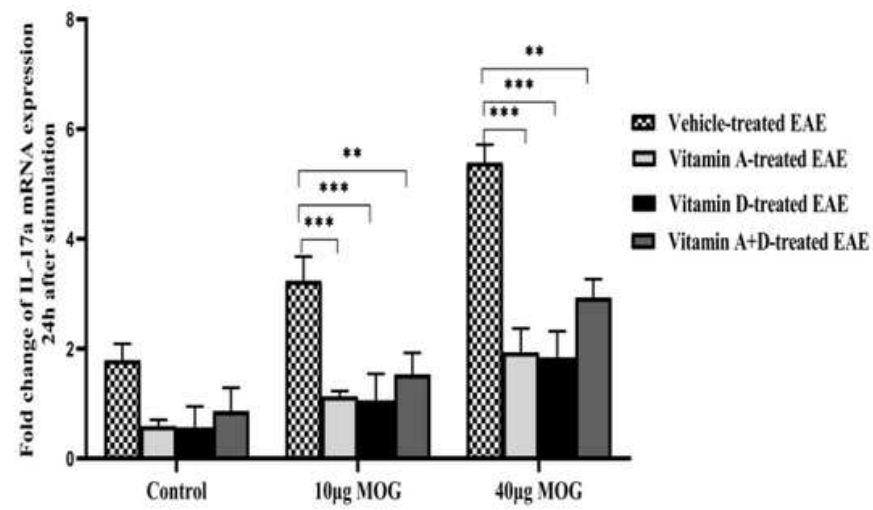

B

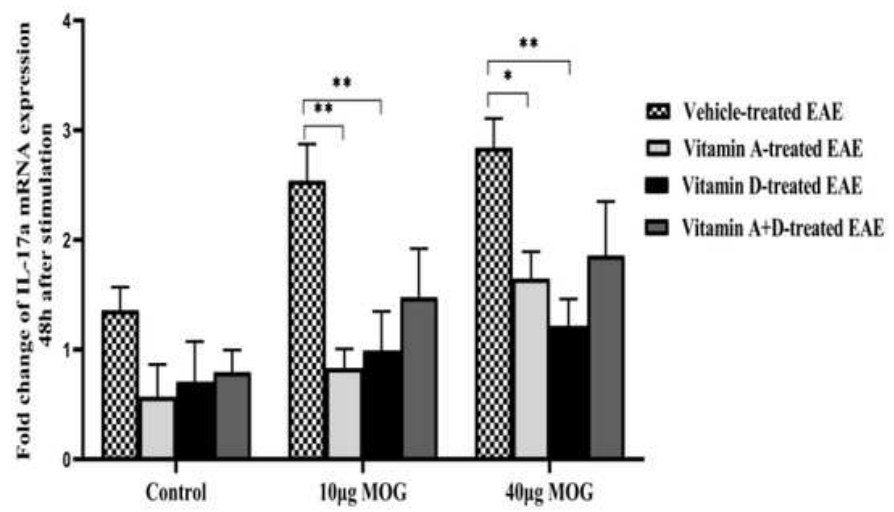

Figure 5

IL-17 expression levels in splenocytes. A IL-17 expression levels in MOG-stimulated splenocytes obtained from different groups. Splenocytes were stimulated with 0 (control), 10, $40 \mu \mathrm{g} / \mathrm{ml}$ of MOG peptide for 24 $\mathrm{h}$ and $\mathrm{B} 48 \mathrm{~h}$. Values are presented as mean \pm SEM, eight mice in each group, ${ }^{\star} p<0.05, * \star p<0.01, \star \star \star *$ p<0.001, Two-way ANOVA, Tukey post hoc.

A

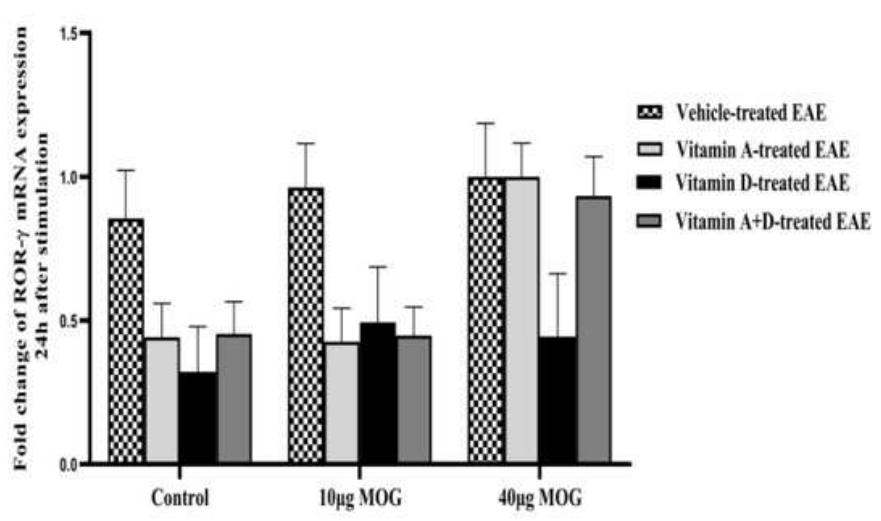

\section{B}

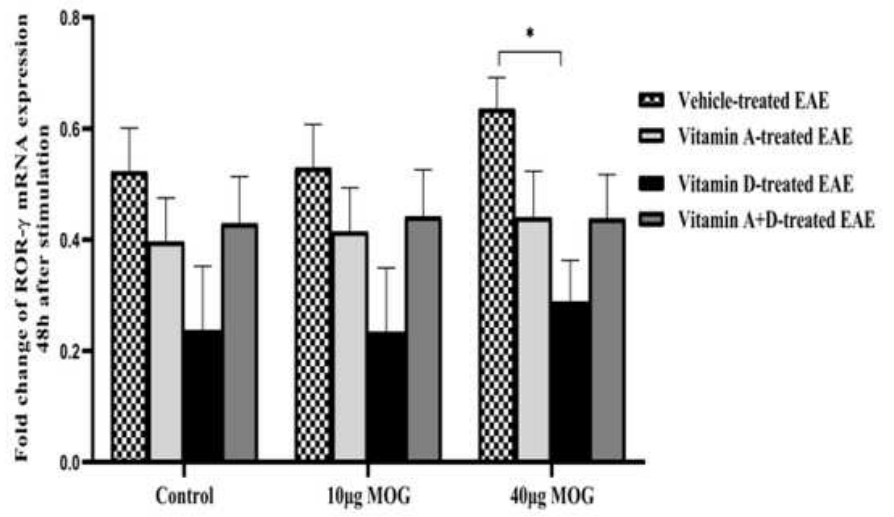

Figure 6

RORyt expression levels in splenocytes. A RORyt expression levels in MOG-stimulated splenocytes obtained from different groups. Splenocytes were stimulated with $0,10,40 \mu \mathrm{g} / \mathrm{ml}$ of MOG peptide for 24 
$h$ and $B 48 \mathrm{~h}$. Values are presented as mean \pm SEM, eight mice in each group, $* p<0.05, * \star p<0.01, * \star \star$ $p<0.001$, Two-way ANOVA, Tukey post hoc.

A

Human RORC ENST00000356728.6 3 ' UTR length: 1401

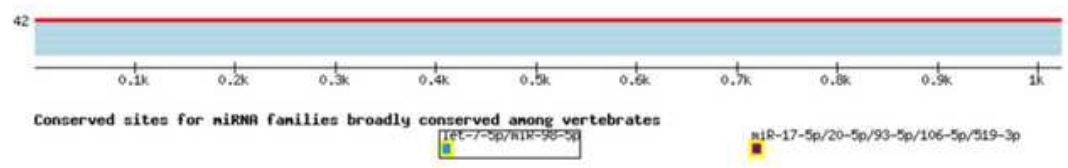

Mouse Rorc ENSMUSTO0000107292.2 3 ' UTR length: 923

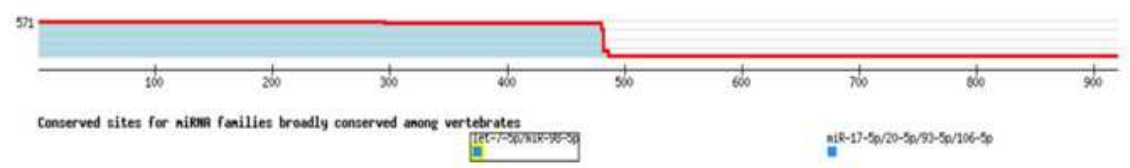

B

$\begin{array}{ll}\text { mmu-miR-98-5p } & \text { UGAGGUAGUAAGUUGUAUUGUU } \\ \text { hsa-miR-98-5p } & \text { UGAGGUAGUAAGUUGUAUUGUU } \\ & \text { UGAGGUAGUAGGUUGUAUAGUU } \\ \text { hmu-let-7a-5p } & \text { UGAGGUAGUAGGUUGUAUAGUU }\end{array}$

c

Position 407-413 or RORC 3. UTR

has-miR-9s-sp

5...AAUAAGCCUUUGAAAUACCUCAU...

3. UUgUUaugungandgangGago

Position $407+413$ or RORC 3 . UTR

Lexa-let-7a-5p

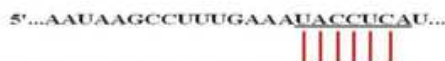

3. vugauaugutggaugangGage

Position 371-377 of RORC 3' UTR

mmu-miR-98-5p

5. ... UaAcaguccuUUcaAuaccucau

3. UUguUAUgUUGAaUgaUgGaGU

Position 371-377 of RORC 3' UTR

mmu-let-7a-5p

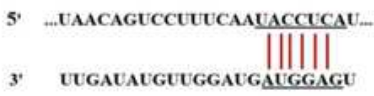

\section{Figure 7}

Potentially targeting miRNA in CNS and splenocyte of mice. A Predicted target sites for miR-98-5p and Let-7a-5p on RORyt mRNA 3' UTR according to TargetScan algorithm. B Homology between human and 
mouse mature miRNA sequences. C Sequence of predicted binding sites for miR-98-5p and Let-7a-5p on 3' UTR of mouse RORYt mRNA.

A

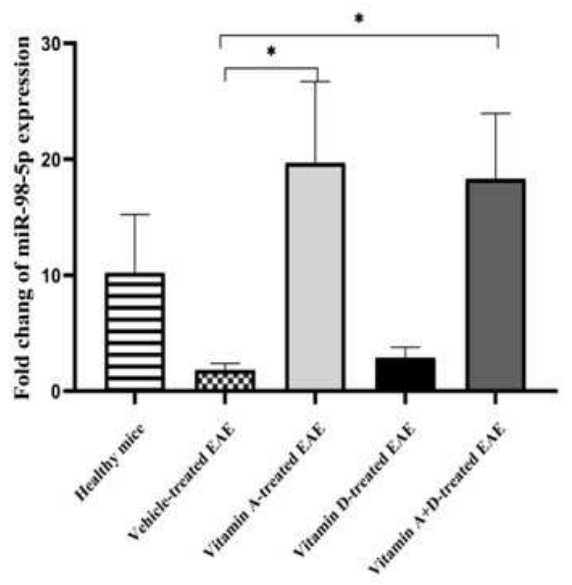

B

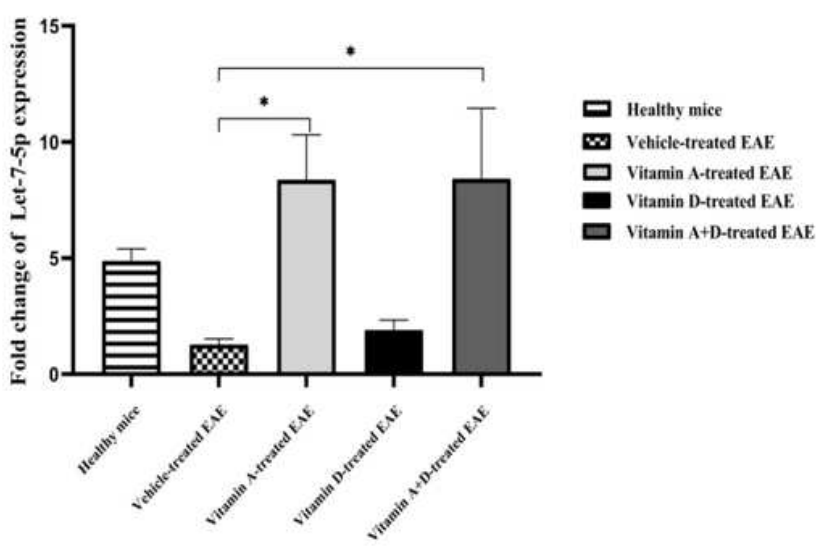

\section{Figure 8}

Expression levels of miRNAs in the spinal cords of different EAE groups. A The expression level of miR98-5P and $B$ Let-7-5P are shown as bar graphs. Values are shown as mean \pm SEM, eight mice in each group, * $p<0.05,{ }^{* *} p<0.01$, *** $p<0.001$, one-way ANOVA, Tukey post hoc.

A

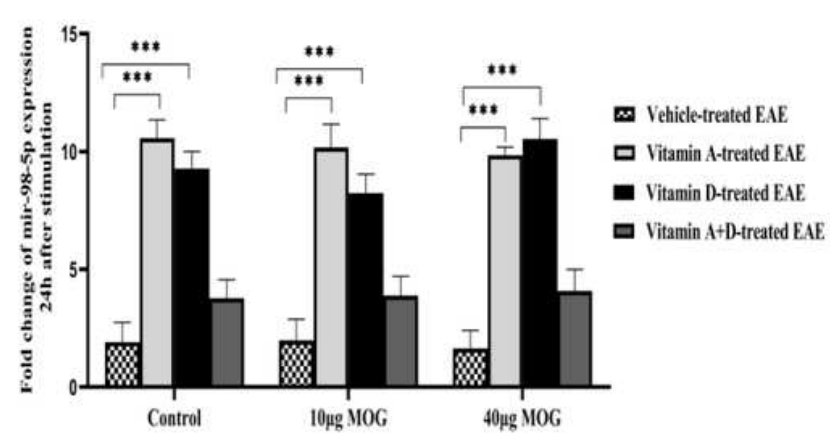

B

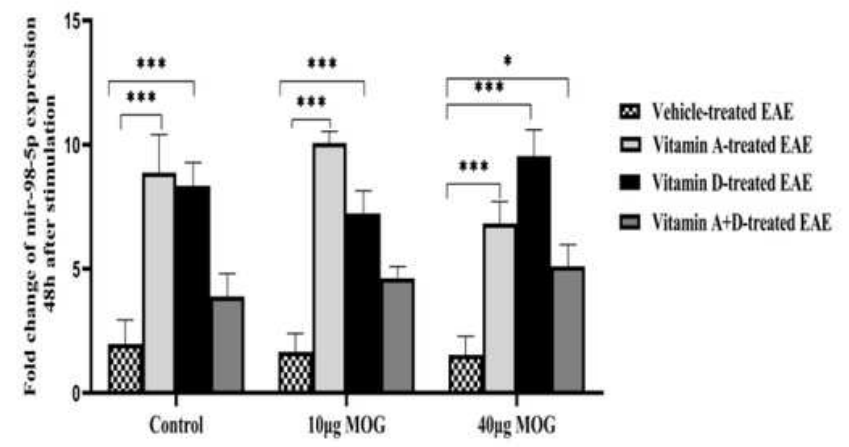

Figure 9

Expression levels of miR-98-5p in MOG-stimulated splenocytes obtained from different groups of animals. A splenocytes Splenocytes were stimulated with 0 (control), 10, $40 \mu \mathrm{g} / \mathrm{ml}$ of MOG peptide for 24 $h$ and $B 48 \mathrm{~h}$. Data are shown as mean $\pm S E M, n=8$. The values were presented as mean $\pm S E M$, eight mice in each group, ${ }^{\star} p<0.05,{ }^{\star *} p<0.01,{ }^{\star \star \star} p<0.001$, Two-way ANOVA, Tukey post hoc 

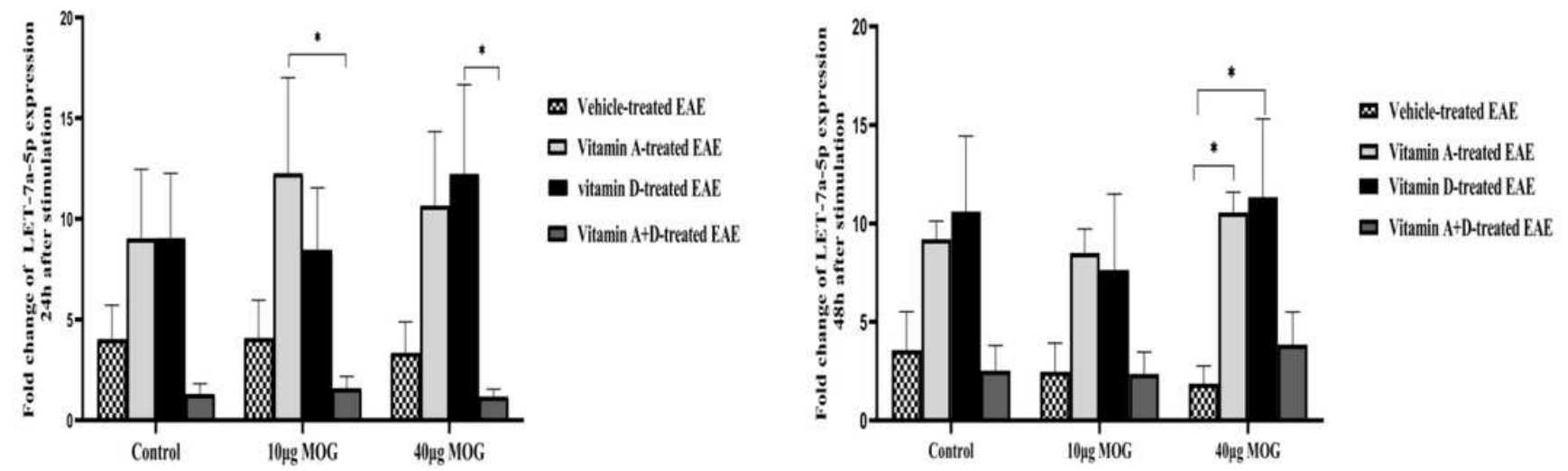

Figure 10

Expression levels of Let-7a-5p in MOG -stimulated splenocytes obtained from different groups of animals. A Splenocytes were stimulated with 0 (control), 10, $40 \mu \mathrm{g} / \mathrm{ml}$ of MOG peptide for $24 \mathrm{~h}$ and B 48 h. Data are shown as mean \pm SEM, eight mice in each group, ${ }^{*} p<0.05, * \star p<0.01, * \star \star p<0.001$, Two-way ANOVA, Tukey post hoc. 
A

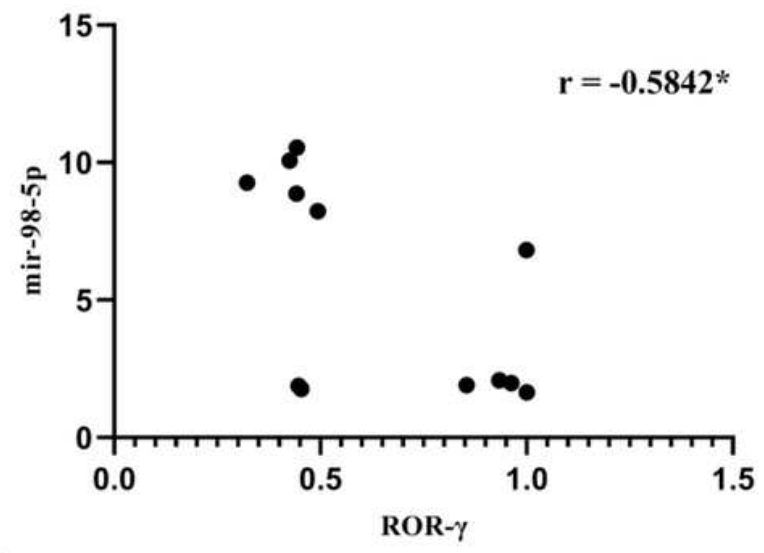

C

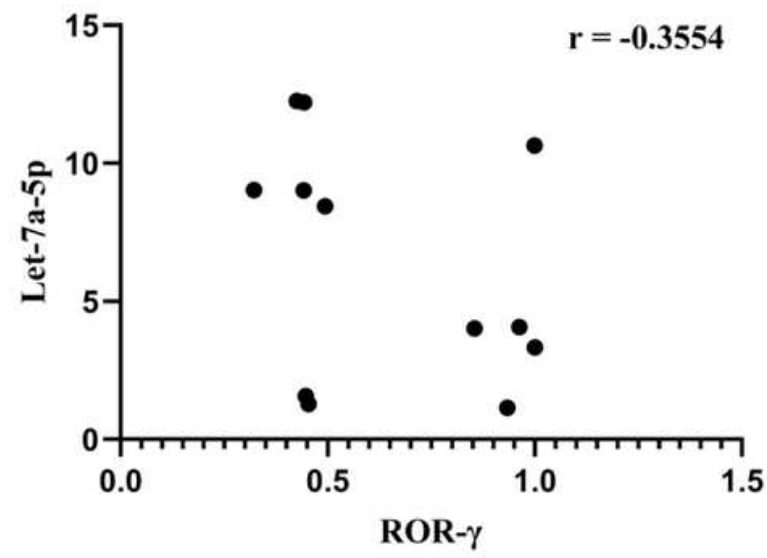

B

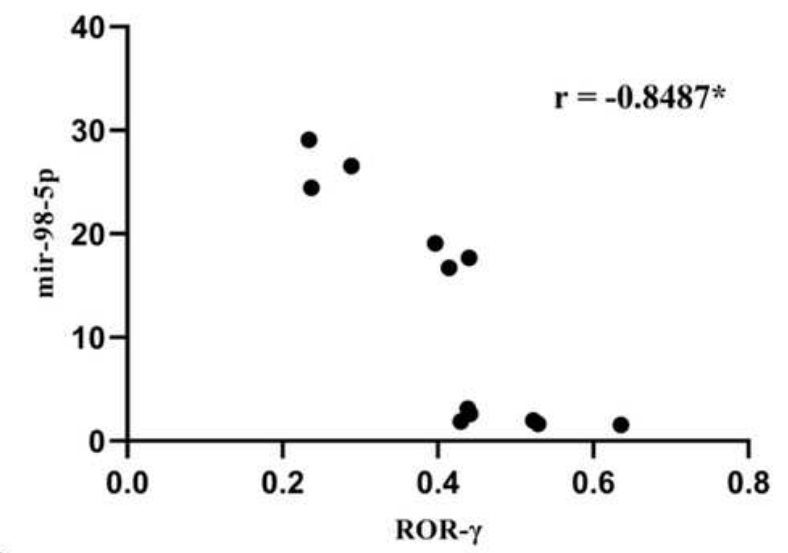

D

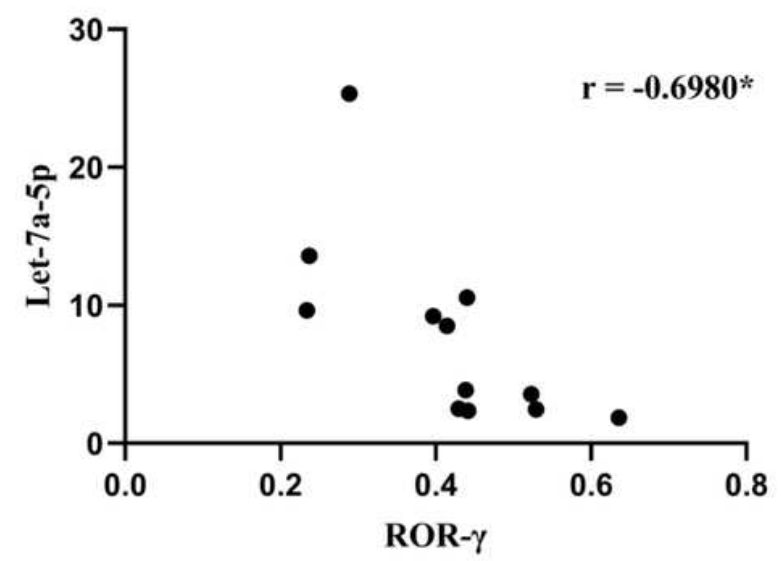

Figure 11

Correlation analysis between RORy mRNA and miRNAs. A Dot plot demonstrates the correlation between RORY mRNA and miR-98-5p in splenocytes $24 \mathrm{~h}$ and B $48 \mathrm{~h}$ after stimulation with MOG peptide. C Likewise, correlation between RORy mRNA and let-7a-5p after $24 \mathrm{~h}$ and D $48 \mathrm{~h}$ of stimulation are shown. (Pearson correlation; ${ }^{*}<0.05, * \star p<0.01$ ).

\section{Supplementary Files}

This is a list of supplementary files associated with this preprint. Click to download.

- Availabilityofdataandmaterials.pdf 